\title{
CORRIGENDUM
}

\section{Image Simulation for Mingantu Ultrawide Spectral Radioheliograph in the Decimetre Wave Range-CORRIGENDUM}

J. Du, Y. Yan, W. Wang, and D. Liu

doi:10.1017/pasa.2015.24, published by Cambridge University Press, June 2015.
In the original publication of "Image Simulation for Mingantu Ultrawide Spectral Radioheliograph in the Decimetre Wave Range," by Jing Du, Yihua Yan, Wei Wang, and Donghao Liu, there were concerns regarding ambiguity of a few statements. To clarify, the authors have submitted an update regarding Table 6 (p. 12) and the supporting language (p. 13):

Tables 5 and 6 show the SNR of the different regions $(a \sim j)$ in the cleaned maps which is produced with MUSER-I with different frequencies or different observation time, the regions selected as the Figure 14 shown. In the snapshot mode, MUSER-I will produce an image every $3 \mathrm{~ms}$. From Table 6, we can see that the SNR of region $a \sim j$ is getting better when the observation time increases, the image quality is getting better.
Table 6. The signal to noise ratio $(\mathrm{dB})$ of the different regions $(a \sim j)$ with different observation time (without considering the system noise). The frequency is $0.4 \mathrm{GHz}$.

\begin{tabular}{|c|c|c|}
\hline \multirow{2}{*}{$\frac{\text { Frequency }}{\text { Observation time }}$} & \multicolumn{2}{|c|}{$0.4 \mathrm{GHz}$} \\
\hline & Snap-shot(3 ms) & $1 \mathrm{~s}$ \\
\hline $\mathrm{a}$ & 33.52 & 35.60 \\
\hline $\mathrm{b}$ & 33.83 & 35.76 \\
\hline $\mathrm{c}$ & 28.96 & 31.32 \\
\hline d & 28.85 & 30.71 \\
\hline $\mathrm{e}$ & 31.36 & 33.09 \\
\hline $\mathrm{f}$ & 29.36 & 31.10 \\
\hline g & 27.84 & 29.54 \\
\hline $\mathrm{h}$ & 31.20 & 33.14 \\
\hline $\mathrm{i}$ & 27.35 & 29.71 \\
\hline $\mathrm{j}$ & 29.85 & 31.22 \\
\hline
\end{tabular}

The authors regret these errors.

\section{Reference}

Du, J., Yan, Y., Wang, W., and Liu, D. (2015) Image Simulation for Mingantu Ultrawide Spectral Radioheliograph in the Decimetre Wave Range. Publications of the Astronomical Society of Australia, 32, 1-13. 